\title{
Design Optimization and Structural Analysis of Multi-Material Truss Structure
}

\author{
Vimal RajV ${ }^{1}$, Milburj Fredol ${ }^{2}$, Agnishwar Jayaprakash ${ }^{3}$, Dhinesh Kumar ${ }^{4}$, \\ Anbu Kumar ${ }^{5}$, Lokesh $^{6}$ \\ ${ }^{1}$ (CEO, GarudaAerospace Pvt. Ltd., India) \\ ${ }^{2}$ (Head fleet operations, GarudaAerospace Pvt. Ltd., India) \\ ${ }^{3}$ (Managing Director, GarudaAerospace Pvt. Ltd., India) \\ ${ }^{4}$ (Head Design, GarudaAerospace Pvt. Ltd., India) \\ ${ }^{5}$ (Fabrication Engineer, Garuda Aerospace Pvt. Ltd., India) \\ ${ }^{6}$ (DesignEngineer, Garuda Aerospace Pvt. Ltd., India)
}

\begin{abstract}
Trusses are supporting structures for heavy loads. An effective design for the truss results in cheap, strong yet light weight structures. These modern days, trusses can be fabricated with different types of metallic and non-metallic materials. We focused on design and fabricating a square truss of span 1.5m, which is analyzed for different materials to get a desired optimum efficient truss design. The support conditions (fixed/hinged) and type of connection (welded/bolted) between truss members are also checked for the forces in truss members. These various truss analyses are performed using analysis software. Later, these analysis results are used for fabricating an efficient truss.
\end{abstract}

\section{Introduction}

Truss is a framed structure formed by joining various members in a particular pattern of triangles depending upon span, type of loading, slope and other requirements. Steel trusses are widely used in industrial buildings for many years. Every structure should have to fulfill the structural and economical requirements. Hence there is need of optimization of truss design to obtain minimum weight. All of the methods used for reducing the weight tend to reach an optimum design having a set of design constraints. The optimum design of a structure should satisfy various constraint limits such as displacement limits, stress and local stability conditions. Structural design is the methodical investigation of the stability, strength and rigidity of structures. The basic objective in structural analysis and design is to produce a structure capable of resisting all applied loads without failure during its intended life. The primary purpose of a structure is to transmit or support loads. If the structure is improperly designed or fabricated, or if the actual applied loads exceed the design specifications, the device will probably fail to perform its intended function, with possible serious consequences. A well-engineered structure greatly minimizes the possibility of costly failures. The aim of this research is to study the variation in truss structural deformation as well as its stiffness when various materials and its combinations are used for fabrication.

Design

A square truss of length $1.5 \mathrm{~m}$ and of $20 \mathrm{~cm}$ width was designed in CATIA v5. L-sections were designed for riveting at each corner with web sections. The final assembly is shown in figure 1.1

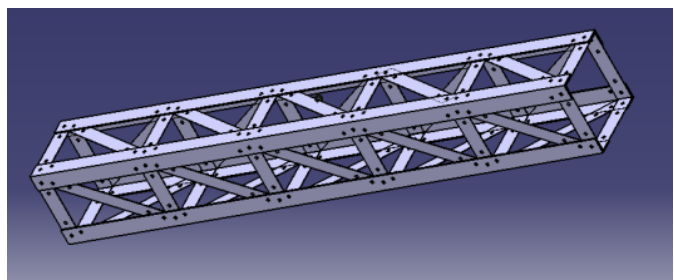

Fig 1.1: CATIA image of 4 side square truss

\section{Structural Analysis}

Choosing a suitable material for fabricating the truss is the fundamental task. Different materials are selected for analysis and deformation of truss for each chosen material has been tabulated. Aluminum, Carbon fiber re-enforced plastic (CFRP), Glass fiber re-enforced plastic (GFRP)and steel were included in the list.Test analysis under self-weight load was conducted for the fabricated CFRP and GFRP models considering the square truss as cantilever beam. Fixing one end to a rigid structure, weight will act through Center of gravity (COG) of designed model. 


\section{Result}

Comparison of deformation for different models were done and given below.

Details:

- Square truss of $20 \times 20 \mathrm{~cm} 1.5 \mathrm{~m}$ long

- Member thickness Chord $1.5 \mathrm{~mm}$ and Web $1 \mathrm{~mm}$

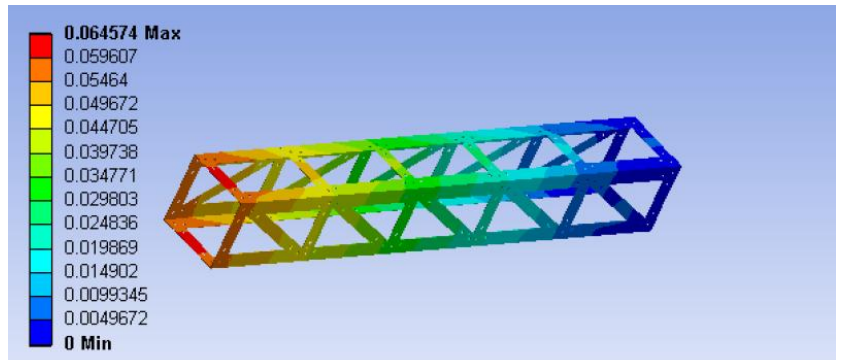

Fig 2.1: Total deformation result of Aluminum truss with GFRP webs under self-weight

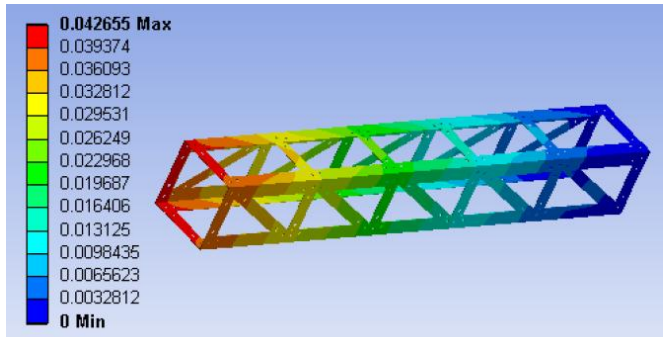

Fig 2.2: Total deformation result of Aluminum truss with CFRP webs under self-weight

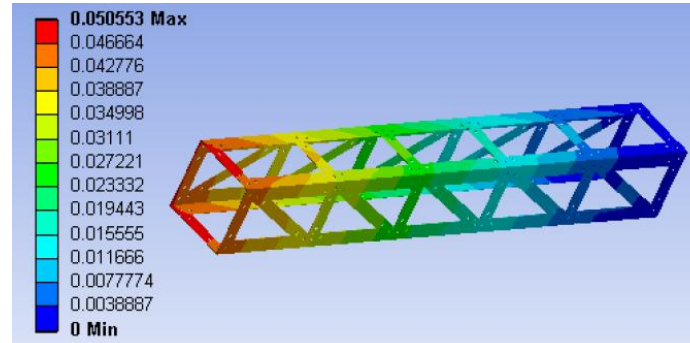

Fig 2.3: Total deformation result of Aluminum truss under self-weight

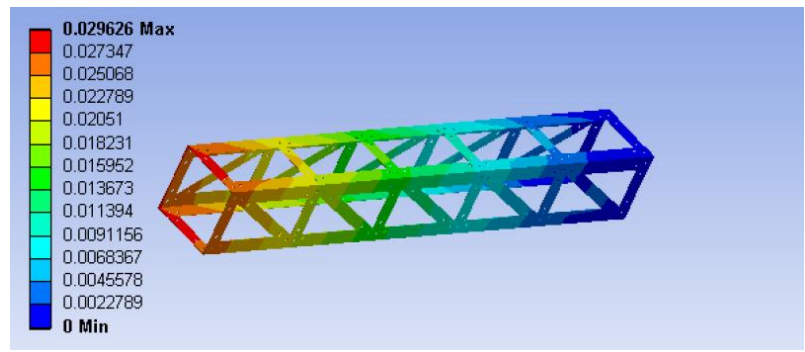

Fig 2.4: Total deformation result of CFRP truss under self-weight

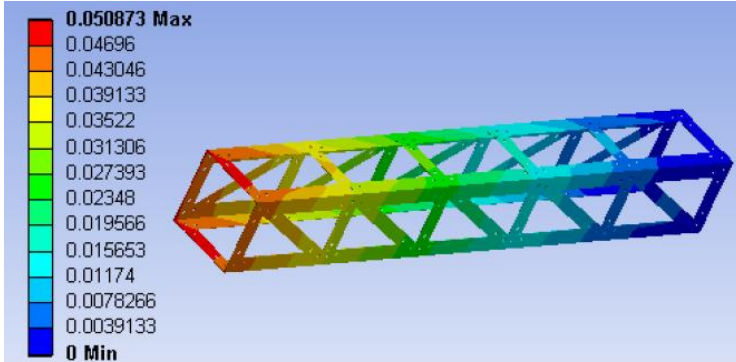

Fig 2.5: Total deformation result of Steel truss under self-weight. 


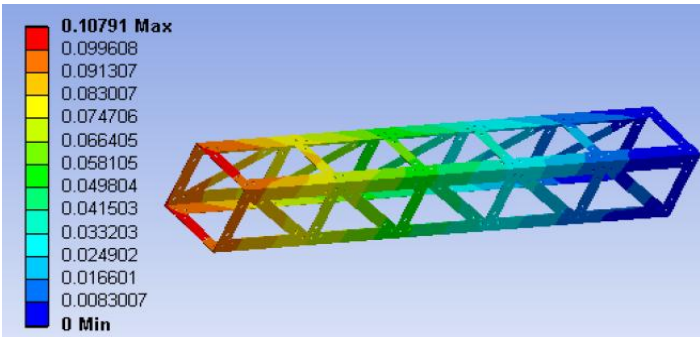

Fig 2.6: Total deformation result of GFRP truss under self-weight

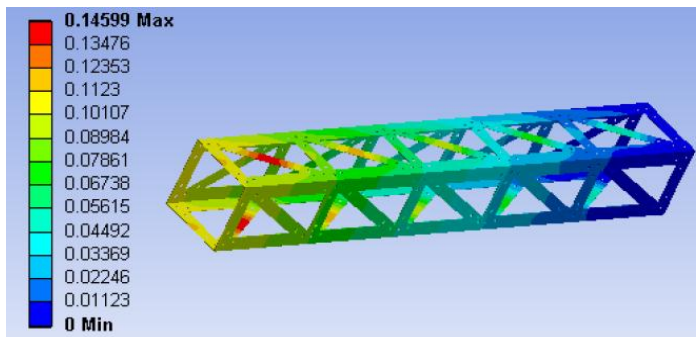

Fig 2.7: Total deformation result of GFRP 4side truss under self-weight.

Table 1: Total deformation results.

\begin{tabular}{|l|l|l|l|}
\hline Sl.No & Material & Mass (kg) & Deformation (mm) \\
\hline 1 & Al chord GFRP web & 2.3778 & .06457 \\
\hline 2 & Al chord CFRP web & 2.1211 & .04265 \\
\hline 3 & Aluminum & 2.4548 & .05055 \\
\hline 4 & CFRP & $\mathbf{1 . 4 1 7 9}$ & $\mathbf{. 0 2 9 6 2}$ \\
\hline 5 & Steel & 6.9568 & .05087 \\
\hline 6 & GPRP & 2.2155 & .10791 \\
\hline 7 & GFPR 4 side truss & 2.4622 & .14599 \\
\hline
\end{tabular}

\section{Conclusion}

For self-weight truss, load applied is proportional to the mass of truss where it is related to the density of material. Truss made in CFRP results in lighter and stiffer than all other combinations. Whereas, Aluminum which is of lesser density (and weight) than steel, results in lesser deformation, which is observed in Table 1. So aluminum can be substituted for steel under low stress applications, which can reduce the total weight of components. Stiffness of truss can be altered by changing the web material.When Al web was replaced with CFRP material, stiffness and overall strength of structure has been improved. Additionally overall weight of truss structure is reduced.

\section{References}

[1]. Nelson, G.L., Manbeck, H.B. \& Meador, N.F. 1988.Light agricultural and industrial structures: analysisand design. AVI Book Co.

[2]. Prasad, I.B. 2000. A text book of strength of materials.20th edition, Khanna publishers.

[3]. Roy, S.K. \&Chakrabarty, S. 2009. Fundamentalsof structural analysis with computer analysis andapplications, S. Chand andCo. Ltd.

[4]. Salvadori, M. \& Heller, R. 1986. Structure inarchitecture: the building of buildings. 3rd edition.Englewood Cliffs, New Jersey, Prentice-Hall.

[5]. Whitlow, R. 1973. Materials and structures. New York, Longman. 